\title{
Conferencia Internacional de Publicaciones Académicas: un espacio para compartir experiencias y plantear nuevos desafíos
}

\section{Anielka Pérez*}

En agosto de 2013 se realizó en México la Cuarta Conferencia Internacional PKP (Public Knowledge Project) sobre publicaciones académicas. El evento, que se celebró por primera vez en América Latina, movilizó a editores de revistas científicas, bibliotecarios, investigadores, desarrolladores de sitios web y promotores del Movimiento de Acceso Abierto a nivel mundial.

La Conferencia, con sede en la Universidad Nacional Autónoma de México, fue un espacio para compartir las experiencias innovadoras que, en temas de publicaciones académicas, los distintos países están desarrollando. El movimiento de acceso abierto, con 10 años de haberse formado, ha venido impactando en los países de Latinoamérica, y la necesidad de preservarlo como un recurso gratuito y no comercial fueron puntos clave de las conferencias.

Los tres días (19, 20 y 21 de agosto) de conferencias, permitieron enriquecer las experiencias, conocer los avances que países como México, Brasil, Argentina, Costa Rica, entre otros, han logrado. Durante las conferencias se habló de cómo Internet influye en la divulgación de la ciencia, el tener un acceso abierto no comercial.

Uno de los puntos que llamó mi atención fue el título de la ponencia de Michael Carroll (American University Washington College of Law) quien habló de publicar con valores antiguos en un ambiente digital, reflejando de manera precisa la influencia que la sociedad de la información ha tenido en la divulgación de la ciencia.

Michael Carroll desarrolló está temática planteando que el acceso abierto es la nueva forma de compartir información. De acuerdo a la Declaración de Berlín, "por acceso abierto se entiende el acceso libre y gratuito vía web a los resultados de investigaciones” (Babini, 2011, p. 32). 
Es evidente que el internet ha modificado la manera de compartir el conocimiento, demandando que cada vez sea más pública la producción científica, pero ahora se demanda que esto no se límite a los artículos científicos, sino a toda forma de publicación. Si décadas atrás lo que no se publicaba en papel no existía, hoy podemos decir que lo que no está en red no existe. Incluso algunas revistas científicas han incursionado en las redes sociales para acercarse más a sus usuarios y tener una comunicación más interactiva. Pero este es un punto que se podría debatir en otro momento.

En este punto retomo parte de la presentación de Dominique Babini (2013), quien en su ponencia presentó una definición de acceso abierto más amplia: "acceso libre y gratuito vía internet a resultados de investigaciones en revistas científicas y académicas, libros académicos, informes de investigación, tesis, ponencias congresos, datos primarios, registros en audio/ videos de investigación”. Lo planteado es una clara alusión a la importancia de los repositorios institucionales como puerta de entrada a la producción científica de las instituciones o centros académicos.

\section{La presencia de Centroamérica}

Realizar la Conferencia de PKP en América Latina fue una oportunidad para que los países de Centroamérica conocieran experiencias cercanas e identificaran iniciativas de publicación que pueden ser replicables en sus centros de estudio. Posiblemente, a excepción de Costa Rica, los demás países de la región avanzan a pequeños pasos en las temáticas del acceso abierto, desarrollo de repositorios institucionales o portales de revistas.

La Conferencia deja algunos retos para Centroamérica y otros países en proceso de desarrollo:

- Es necesario que desde las instituciones académicas se realice mayores estudios sobre el estado actual de las publicaciones, así como el impacto o aceptación del acceso abierto.

- Se debe promover la creación de repositorios institucionales con una visión de compartir la producción científica que se genera con las investigaciones desarrolladas.

- Es necesario garantizar la calidad de los contenidos de la información, así como los procesos de evaluación por pares.

- Debemos realizar acciones con visión de nación para tener una mayor fortaleza de las iniciativas propuestas.

\section{La experiencia de Nicaragua}

En 2006 surge en Nicaragua el Programa para el Fortalecimiento de la Información para la Investigación (Perii). Con el apoyo de la Red Internacional para la Disponibilidad de Publicaciones Científicas (INASP), el acompañamiento de Perii ha permitido que las publicaciones nicaragüenses mejoraran sus procesos editoriales, lograran una indización en el Portal de Portales LatIndex, y en la actualidad gestionen otras indizaciones y nuevas revistas trabajen para cumplir con los criterios de LatIndex. 
Los avances han sido significativos, pero la experiencia de PKP obliga a identificar nuevos desafíos además de los ya mencionados a nivel de Centroamérica. Un punto clave es cuidar la calidad de la publicación científica, manteniendo e incorporando (para quienes todavía no tienen) una revisión arbitrada con la aspiración de que las publicaciones alcancen cada día mayor reconocimiento internacional.

Uno de los desafíos importantes es el portal de revistas de Nicaragua. Desde el año pasado se iniciaron esfuerzos por tener portales de revistas nacionales. Sin embargo, es necesario que los editores o gestores de revistas aporten a su actualización y generen más su divulgación.

Desarrollar estrategias que mejoren el tráfico en los sitios web de las publicaciones es un segundo desafío. Es un momento clave para aprovechar todas las herramientas tecnológicas para facilitar, a la mayor cantidad de personas, el acceso a las diversas publicaciones científicas.

La Internet ha creado nuevos espacios de interacción y determinado nuevas formas de comunicación. La ciencia no está fuera de esta dinámica, Internet está ofreciendo una poderosa herramienta para divulgar su quehacer. "Las revistas académicas electrónicas se han establecido ya como un nuevo mecanismo de difusión y acceso al conocimiento" (Alonso-Gamboa, 2010).

\section{Agradecimiento}

La participación de representantes de Honduras y Nicaragua en la Conferencia de PKP fue posible por una beca del proyecto INASP. Por ello, tres representantes de cada país pudimos estar presentes. Como miembro del equipo de la revista Encuentro, reafirmo el agradecimiento y sabemos que lo aprendido en la Conferencia nos permitirá seguir mejorando y motivando a otras revistas de la Universidad Centroamericana a incorporar en sus procesos editoriales criterios de calidad con reconocimiento internacional.

\section{Referencias bibliográficas}

Alonso, G. (2010). Perspectivas de las revistas académicas electrónicas en México. Revista Digital Universitaria, 12 (11). Recuperado el 05 de octubre de 2013, de http://www.revista.unam.mx/vol.11/num12/art116/art116.pdf

Babini, D. (2011) Acceso Abierto a la producción Científica de América Latina y el Caribe. Identificación de principales instituciones para estrategias de integración regional. Revista CTS, 17 (6), (pp. 31-56).

Babini, D. (2013). Por un acceso abierto no comercial: perspectiva desde una región en desarrollo. Trabajo presentado en la Conferencia de PKP, sobre Publicaciones Académicas, México, 19-21 de agosto, (paper). 